\title{
Analysis of infant rescue breathing performance errors during trainin that lead to poor quality CPR
}

\author{
Cynthia Rojero, Allen Kuo, Mankam Chin
}

\section{Background and Introduction}

There are few articles on the study of pediatric ventilations that cover the skill of ventilation itself. One article analyzed the issue of hyperventilation during skills training, and another how corrective feedback and target score during training can increase the quality of CPR. In addition, the American heart Association ( $\mathrm{AHA}$ ) has been recommending the use of feedback simulations during training and recently they have begun to require it. This data was collected from different AHA training center hospitals and pediatric specialist to see what are the main performance related errors in ventilations. Performed ventilations are broken down into three parts and individual ventilations are analyzed according to the AHA guidelines.

\section{Methods}

A total of 70 Neonate and PALS specialists from different AHA training hospitals were tested during their regular recertification as per guidelines. An infant simulator with sensitive and accurate sensors that measure analog movements and converts that into digital data was used for both pre-test and post-test. During the pre-test specialists were asked to perform their skills on the simulator as normal without any live feedback (blind). When finished they were shown their simulation performance scores. Specialists were given an AHA guidelines review, brief explanation of the simulator's live feedback system then asked to perform with access to view the live feedback. They were given a target score of $60 \%$.

Three components of ventilations are examined: rate of air given, volume of air given, and intervals between air given. They were evaluated as a percentage compliant with the guidelines.

To examine whether there was a difference in performance level between the sub-skills, a two tail t-test and a z-test we run. Percentage compliant sub-skill scores were then compared for pre-test and post-test.

\section{Results}

Pre-Test averages for each ventilation had a correct volume of $16.45 \%$; the correct rate of air given averaged $30.32 \%$; and intervals between ventilations averaged $23.87 \%$. All compliances were to the standard of AHA guidelines.

Post-Test averages for each ventilation had correct volume of 92.37\%; rate of air given averaged $71.56 \%$; interval between ventilations averaged $78.76 \%$. All compliances were to the standard of AHA guidelines

\section{Pre-Test Ventilation Compliant / Non-Compliant Detail}

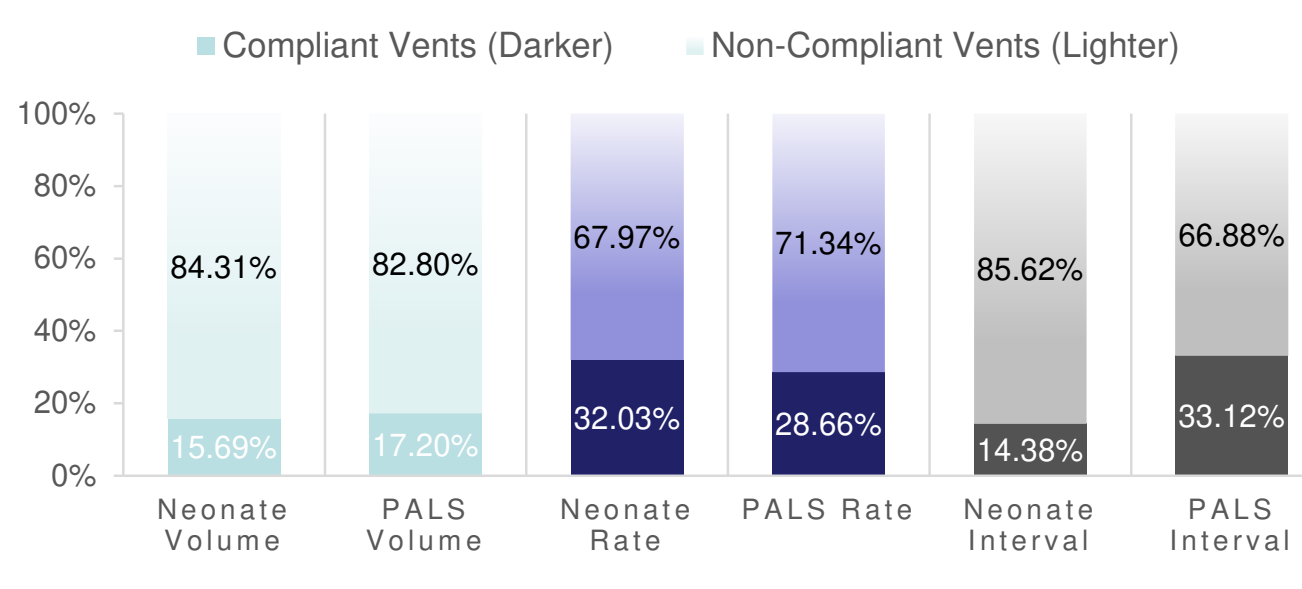

Unpaired t-test resulted in $\mathrm{P}$ value less than 0.0001 for all three sub-skills in their pre-test and post-test comparison.

For interactive relationship between volume of air given and rate of air given pre-test had a $p$ value equal to 0.0143 with a confidence interval difference of -10.400 . Post test $p$ value is less than 0.0001 with a confidence interval difference of 23.8

In the post-test Neonate specialist scored a compliance percentage of $93.11 \%$ in Volume, $72.75 \%$ in rate air is given, and $74.67 \%$ in intervals between air given. PALs specialist scored a compliance percentage of $91.52 \%$ of volume, $70.22 \%$ in rate air is given, and $83.39 \%$ in intervals between air given.

\section{Discussion and Conclusion}

This analysis of pediatric ventilations suggest that using a real time feedback simulator markedly improves performance skills. Using target scores along with real time feedback direct effort in attainment of skills. Considering both Neonate and PALs specialist had similar post exam scores demonstrates the ability to achieve high marks despite specialization, but further research is needed in comparison of specialist and in retention of skills.

\begin{tabular}{|r|c|c|c|c|}
\hline & \multicolumn{2}{|c|}{ Pre-Test (No.) } & \multicolumn{2}{c|}{ Post-Test (No.) } \\
\hline Size $(\mathrm{n})=70$ & $\begin{array}{c}\text { Compliant } \\
\text { Vent }\end{array}$ & Total Vent & $\begin{array}{c}\text { Compliant } \\
\text { Vent }\end{array}$ & Total Vent \\
\hline Max (\%) & 7 & 31 & 53 & 60 \\
\hline Min (\%) & 0 & 1 & 7 & 12 \\
\hline Range (\%) & 7 & 30 & 46 & 48 \\
\hline Median (\%) & 0.3 & 4.4 & 17.9 & 26.6 \\
\hline Variance Pop & 1.0 & 26.0 & 125.5 & 252.4 \\
\hline Stdev. Pop & 1.0 & 5.1 & 11.2 & 15.9 \\
\hline $\begin{array}{r}\text { Std Error of } \\
\text { Mean }\end{array}$ & 0.1 & 0.6 & 1.3 & 1.9 \\
\hline
\end{tabular}

\section{Post-Test Ventilation Compliant / Non-Compliant Detail}

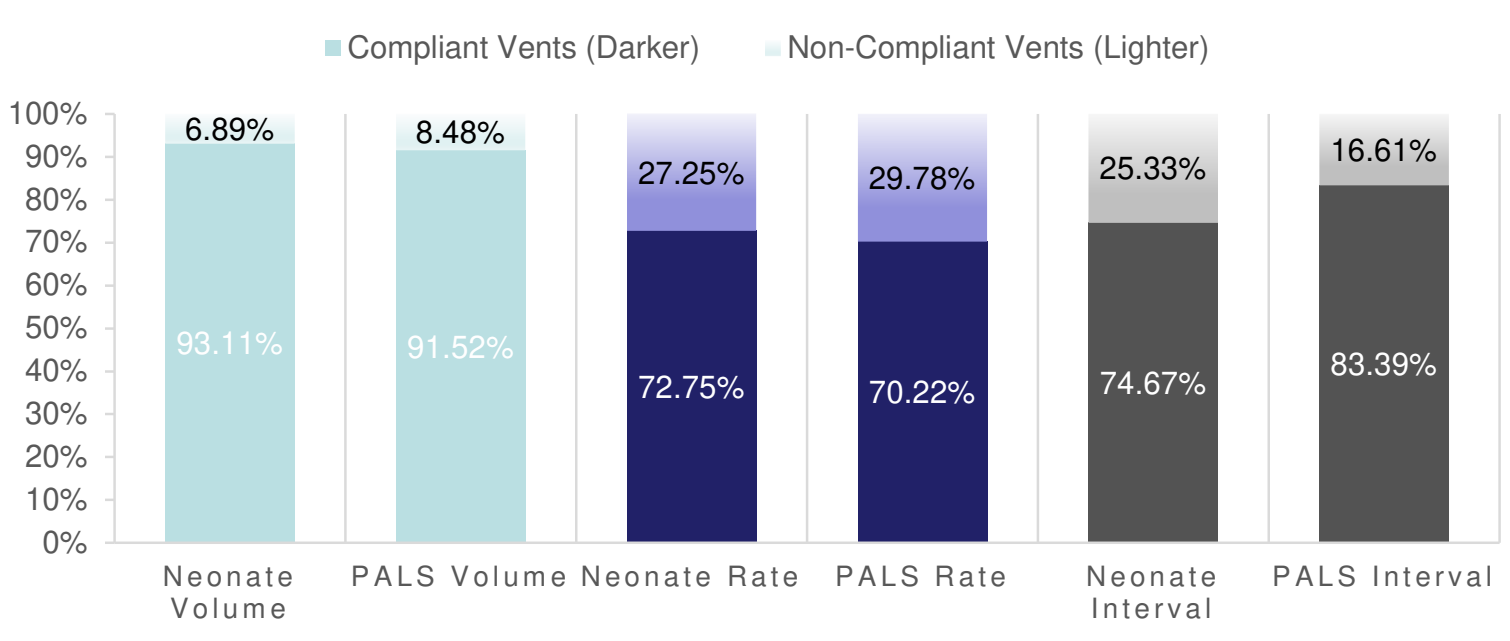

